\title{
EJNSO
}

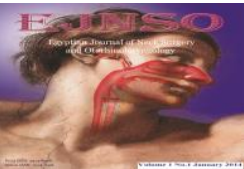

\section{Does Intelligence Predict Language Development?}

Eman Moustafa, MD.

Phoniatric Unit, ENT Department, Sohag University

Keywords: Language, Intelligence, I.Q, Stanford

Binet, intelligence parameters.

\begin{abstract}
Aims: a) To investigate the relationship between language and different intelligence parameters, b) To evaluate if different intelligence parameters can predict language in children. Background: Knowledge of language has been considered as the principle basis of intelligence. Assessment of the relation between different parameters of intelligence and language was not previously studied. Material and Methods: A cross sectional study of 47 children with delayed language development (DLD) aged 2 to 6 years was recruited from the phoniatric unit. All children had undergone Intelligence Quotient (I.Q) assessment using Stanford Binet (IV edition) and Arabic language test (ALT). Results: No correlation was found between receptive language age and different intelligence parameters. Expressive language age showed moderate correlation with total I.Q ( $\mathrm{r}=0.5)$, short term memory $(\mathrm{r}=0.4)$ and strong correlation with verbal reasoning $(\mathrm{r}=0.6)$ Conclusion: There is no parameter in the intelligence test that can predict later language progress. Knowing that there is some intelligence parameters that are correlated with language may help us provide programs to strengthen the stronger area, and at the same time provide opportunities to enhance the learning process in the less strong areas in children with delayed language development.
\end{abstract}

\section{INTRODUCTION:}

Sternberg ${ }^{1}$ defined intelligence as a measure of a person's ability to acquire the knowledge and skills that will allow that person to adapt to his/her environment. Therefore, knowledge of language has been considered as the principle basis of intelligence. ${ }^{2}$ As the psychologist Steven Pinker ${ }^{3}$ stated "language is the jewel in the crown of cognition". Although intelligence has been considered as one of the important factors affecting learning in general, and learning of language in particular, Albert Einstein had language learning disabilities.

Thus, general intelligence or what Spearman $^{4}$ called the "g" factor alone cannot explain specific disabilities or specific talents. Despite of the general 
agreement among psychologists that "g" exists; there is also evidence for specific intelligence "s", a measure of specific skills in narrow domains. Einstein is an example of asynchronicity in early cognitive development in which his accomplishment contradicts his initial delay. Geschwind and Galaburda ${ }^{5}$ suggested that the delay in development of the left hemisphere, in which language areas exit, may allow the right hemisphere that mediates spatial computations, to become highly specialized. Einstein's creativity was heavily dependent on spatial reasoning, and the abnormal development of his left hemisphere may have allowed his right hemisphere to become highly specialized for spatial computations.

Sternberg $^{6}$ had proposed triarchic (three-part) theory of intelligence; analytical intelligence, creative intelligence, and practical intelligence. Also, Howard Gardner ${ }^{7,8}$ introduced "Multiple intelligence" theory in which there are eight intelligences that can be differentiated from each other (linguistic, logico-mathematical, spatial, musical, kinesthetic, interpersonal, intrapersonal, and naturalistic). The stronger type of intelligence may work with weaker types of intelligences to develop skills and solve problems. Hence, if the delayed language developed (DLD) children have poor linguistic intelligence, they may have other stronger abilities and skills that could help them develop language. Also, Guilford9 recognized a strong aspect of intellectual functioning which does not imply strength in other aspects. This fact urged the author to investigate which aspect of intellectual functioning would contribute to language proficiency.
Karmiloff and Karmiloff-Smith ${ }^{10}$ have disagreed with any separation of language from general intelligence. Although children with Williams syndrome have low general intelligence, they are able to speak in complex syntax and rich vocabulary. Yet, comprehension of complex sentences in those children is affected. They suggested that good auditory memory may account for such observations. Therefore, in their point of view, auditory defects explain other language disorders such as specific language impairment.

Because of the conflicting opinions of the relationship between language and intelligence and because assessment of the relation between different parameters of intelligence and language was not previously studied, this study was conducted. Also, it explores which parameter can be a predictor of language development. Not only understanding the relation between language and intelligence help the phoniatricians/ speech language pathologists to understand the problems associated with children with delayed language development and to evaluate their points of strength and weaknesses but also help predict language progress during therapy.

\section{Material and Methods}

Ethical considerations: The ethics committee of Sohag University approved the study. A written consent to participate and to publish was taken from all patients or participants before our study procedures. None of the authors have any competing interests.

A cross sectional study of 47 children with delayed language development aged 2 to 6years was recruited from the phoniatric unit. Inclusion criteria: I. $Q \geq 70$; exclusion criteria: mental retardation, neuropsychological disorders and 
developmental disorders. All children had undergone the following:

-Intelligent Quotient (I.Q) using Stanford Binet (IV edition).11The test will provide the following scores: I.Q; and four factors of cognitive ability

The total IQ quotient was classified according to the Arabic version into mentally retarded $(\leq 69)$, borderline intelligence (70-79), low average (80-89), average (90-109), above average (110-119), Superior (120$129)$ and gifted $(\geq 130)$

-The Verbal Reasoning score reflects the ability to apply verbal skills to new situations. It examines verbal knowledge and understanding.

-The Abstract/Visual Reasoning score measures the ability to understand and perform mathematic operations, the ability to visualize patterns, visual/motor skills, and problem-solving skills.

-The Quantitative Reasoning score examines numerical reasoning, concentration, and knowledge and application of numerical concepts.

-The Short-Term Memory score examines concentration skills, shortterm memory, and sequencing skills. Visual short-term memory and auditory short-term memory for both sentences and number sequences are measured in this area.

-Arabic language test (ALT) 12in which Receptive language age and Expressive language age are calculated.

Statistical analysis: Statistical package for social Sciences version 16 (SPSS, INC, Chicago, IL) under windows was used for data entry and analysis. Descriptive statistics were done for continuous variables by mean, standard deviation $( \pm \mathrm{SD})$. Pearson's correlation was used to assess the association between the different parametric data and multiple linear regression test was also used. For all tests a probability (p) value less than 0.05 was considered significant.

\section{Results}

Forty-seven children were recruited in this study with age mean \pm SD $(53 \pm 11.4$ months). Table (1) and (2) show descriptive statistics of the study group.

Table (1): Number and percentage of the gender in the study group

\begin{tabular}{|l|l|}
\hline & $\mathrm{N}(\%)$ \\
\hline females & $10(21)$ \\
\hline males & $37(79)$ \\
\hline Total & $47(100)$ \\
\hline
\end{tabular}

On the other hand, there is strong correlation between expressive language age and verbal reasoning ( $\mathrm{r}=0.6$ ) (figure 2) and moderate correlations between expressive language age and total I.Q ( $\mathrm{r}=$ $0.5)$ and short-term memory $(\mathrm{r}=0.4)$ (table 4).

Trying to predict expressive language age, t-score of the multiple linear regression test is not significant in total I.Q, verbal reasoning and short-term memory but it shows significant scores in abstract/visual reasoning and Quantitative reasoning $(\mathrm{t}=0.036$, $\mathrm{t}=0.037$ respectively) (table 5 ). 
Table (2): Descriptive statistics of total I.Q, receptive and expressive language age.

\begin{tabular}{|l|l|l|l|l|}
\hline & Minimum & Maximum & Mean & SD \\
\hline Total I.Q & 70 & 154 & 98.62 & 17.390 \\
\hline receptive language age & 28.84 & 49.20 & 40.25 & 5.92 \\
\hline expressive language age & 9.61 & 57.11 & 33.76 & 12.22 \\
\hline
\end{tabular}

No correlation between receptive language age and different intelligence parameters (figure 1) was found. Also no parameter could predict the receptive language age(Table 3).

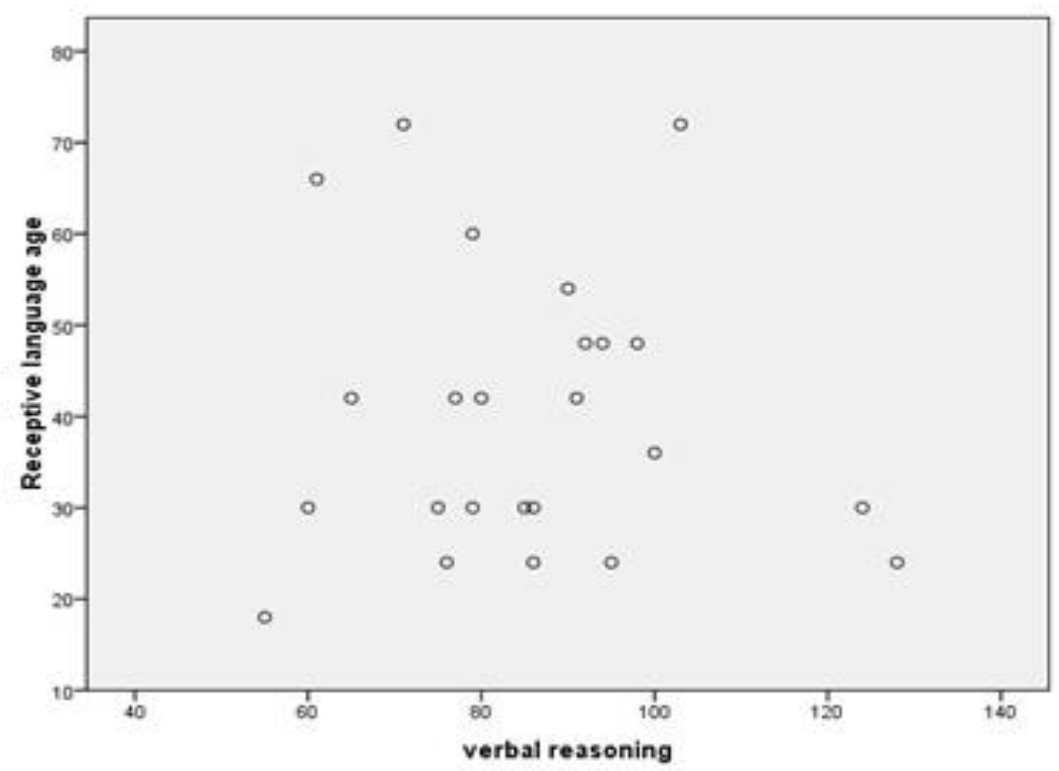

Figure (1): No correlation between Receptive language age and verbal reasoning $(1=-0.07)$. 
Eman Mostafa

EJNSO, Vol.4 No.1; June 2018

Table (3): correlation between receptive language age and different intelligence parameters

\begin{tabular}{|l|l|}
\hline & Receptive language age \\
\hline Total IQ & .095 \\
\hline verbal reasoning & -.074 \\
\hline abstract/visual reasoning & .264 \\
\hline Quantitative reasoning & .098 \\
\hline short term memory & .252 \\
\hline
\end{tabular}

Table (4): Correlation between expressive language age and different intelligence parameters

\begin{tabular}{|l|c|}
\hline & Expressive language age \\
\hline Total IQ & 0.552 \\
\hline verbal reasoning & 0.638 \\
\hline abstract/visual reasoning & -.040 \\
\hline quantitative reasoning & 0.018 \\
\hline short term memory & 0.428 \\
\hline
\end{tabular}


Eman Mostafa

EJNSO, Vol.4 No.1; June 2018

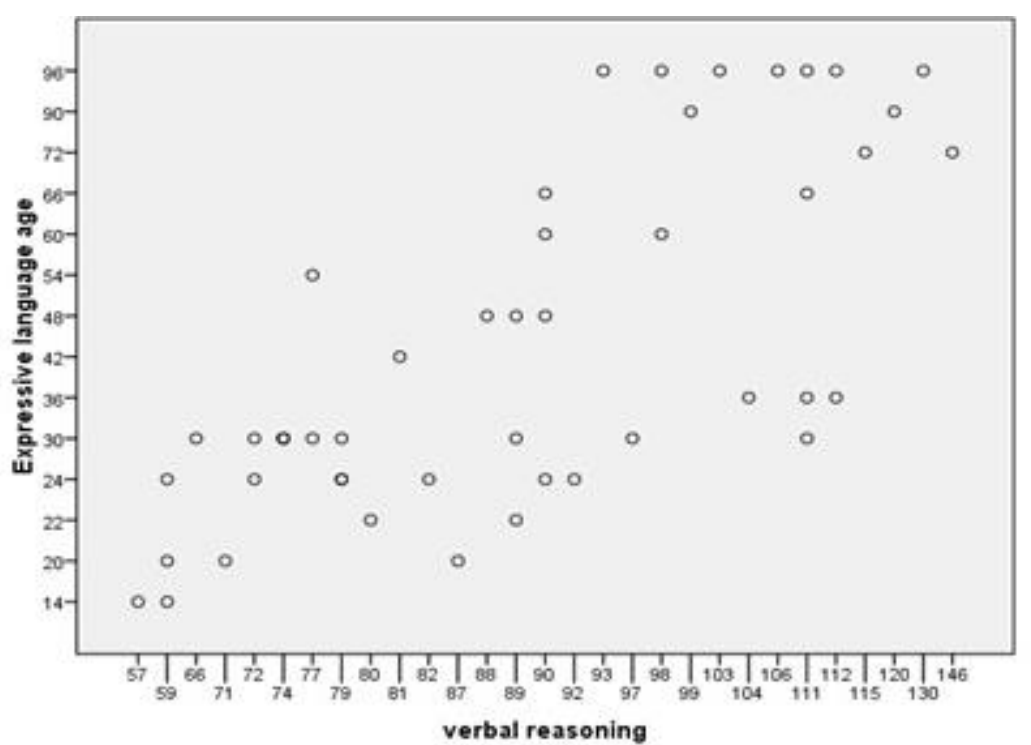

Figure (2): strong correlation between expressive language age and verbal reasoning $(r=0.6)$.

Table (5): Multiple linear regression with the expressive language age as dependent variable $(\mathrm{N}=47)$

\begin{tabular}{|c|c|c|c|c|c|c|c|}
\hline \multirow[b]{2}{*}{ Model } & \multicolumn{2}{|c|}{ Unstandardized Coefficients } & \multirow{2}{*}{$\begin{array}{c}\begin{array}{c}\text { Standardized } \\
\text { Coefficients }\end{array} \\
\text { Beta }\end{array}$} & \multirow[b]{2}{*}{$\mathrm{t}$} & \multirow[b]{2}{*}{ Sig. } & \multicolumn{2}{|c|}{$\begin{array}{l}95 \% \text { Confidence Interval } \\
\text { for B }\end{array}$} \\
\hline & B & Std. Error & & & & $\begin{array}{l}\text { Lower } \\
\text { Bound }\end{array}$ & $\begin{array}{l}\text { Upper } \\
\text { Bound }\end{array}$ \\
\hline 1 (Constant) & & & & & & & \\
\hline & $-1.781-$ & 57.306 & & $-.031-$ & .976 & $-121.724-$ & 118.163 \\
\hline Total IQ & 1.682 & .890 & 1.265 & 1.891 & .074 & $-.180-$ & 3.544 \\
\hline verbal reasoning & - & .457 & $-.329-$ & $-.651-$ & .523 & $-1.253-$ & .658 \\
\hline $\begin{array}{l}\text { abstract/visual } \\
\text { reasoning }\end{array}$ & - $-934-$ & .413 & $-.636-$ & $-2.263-$ & .036 & $-1.797-$ & -.070 \\
\hline $\begin{array}{l}\text { Quantitative } \\
\text { reasoning }\end{array}$ & -690- & .308 & $-435-$ & $-2.241-$ & .037 & $-1.335-$ & -.045 \\
\hline short term memory & .748 & .764 & .202 & 979 & .340 & $-.851-$ & 2.347 \\
\hline
\end{tabular}




\section{Discussion}

Abstract reasoning is thought to be a good measure of general intelligence as it tests the ability to perceive and manipulate relationships of shapes or symbols with no need of language. This study showed no correlation between receptive and expressive language age and abstract reasoning. This is explained by knowing that abstract reasoning is composed of visual questions which are independent of language. Nevertheless, the results showed it can be used as a predictor of proficiency of language.

Jersild ${ }^{13}$ questioned whether the child achieves high scores on verbal intelligence tests because of his/her mastery of the language or his/her mastery of the language is due to good verbal intelligence. In this study, all children with DLD performed poorly in verbal reasoning. It has been noted by Vygotsky $^{14}$ that language facilitates thought as children (around age three or four) use the language that is developed to organize their thoughts and actions. Thus, the poor linguistic abilities of children, in this study, may have affected the verbal reasoning abilities not vice versa.

Verbal Reasoning test measures the child's ability to engage with the language medium in order to identify their wider reasoning ability and potential. Moreover, verbal reasoning focuses on the child's skills in verbal thinking. In the current study, there was strong correlation between expressive language age and verbal reasoning because the test measures the ability to apply verbal skills to new situations. Yet, there was no correlation between receptive language age and verbal reasoning. Since verbal reasoning measures verbal knowledge and understanding, it is not clear why there is no correlation between both variables. Further studies using larger number of children are mandatory to reach to a reasonable and acceptable explanation.

Short-term memory (STM) is memory that is limited to a few seconds in duration. It is assessed by requesting repetition of a series of digits, words, or no words (verbal domain) or repeating a pattern for touching blocks (visual domain). Verbal short-term memory has been specifically linked to learning the phonological forms of new words 15 , and it is possible that such difficulties would disrupt language learning.

Many researchers found moderate correlation between phonological shortterm memory (PSTM) and vocabulary in Typically Developed (TD) children aged four to eight years. ${ }^{13}$ These findings are compatible with the current study as it found moderate correlations between expressive language age and short-term memory.

Some researchers refuse to interpret these data as a causal relationship between PSTM and vocabulary acquisition. ${ }^{16,17,18}$ It is important to note that correlation does not imply causality as short-term memory failed to be a predictor for expressive language age.

Language assessment tasks need both language and memory abilities. Yet, it is difficult to differentiate whether the cause of poor language skills of a child is due to primary language trait or due to verbal short-term memory. ${ }^{19}$ The ability to differentiate between both deficits may help to use the most appropriate way of intervention for children with DLD.

Knowing that total I.Q, verbal reasoning and short-term memory failed to predict later expressive and receptive language age helps us to understand that low scores in total I.Q, verbal reasoning 
and short-term memory do not necessarily result in poor language abilities and vice versa.

Rescale \& Roberts ${ }^{20}$ and Rice et al. ${ }^{21}$ reported that early non-verbal IQ was not predictive of later language outcomes while Ellis Weismer et al. ${ }^{22}$ reported that it did add predictive accuracy. Price et al. $^{23}$ conducted a major twin study which indicated that there is general independence of genetic effects on language and cognitive abilities at age two years, despite some interrelationships.

Conclusion:

There is no parameter in the intelligence test that can predict later language progress. Knowing that there is some intelligence parameters that are correlated with language may help us provide programs to strengthen the stronger area, and at the same time provide opportunities to enhance the learning process in the less strong areas in children with delayed language development.

\section{References}

1- Sternberg, R. J. (1997). Thinking styles. New York: Cambridge University Press.

2- Oller, J.W. (1981). Language as intelligence? Language Learning, 31, 465-492.

3- Pinker, S. (1994). The language instinct. New York: Morrow.

4- Spearman, C. (1905). General Intelligence. Objectively determined and measured. American Journal of Psychology, 15: 210-93.

5- Geschwind, N., Galaburda, A.M. (1985). Cerebral lateralization. Biological mechanisms, associations and pathology. A hypothesis and program for research. Archives of Neurology, 42: 428-59, 634-59.
6- Sternberg, R. J. (1985). Beyond IQ: A triarchic theory of human intelligence. New York, NY: Cambridge University Press.

7- Gardner, H. (1983). Frames of mind: The theory of multiple intelligences. New York, NY: Basic Books;

8- Gardner, H. (1999). Intelligence reframed: Multiple intelligences for the 21st century. New York, NY: Basic Books

9- Guilford, J.P. (1959). Three faces of intellect. American Psychologist, 14, 469-479.

10- Karmiloff, K. and KarmiloffSmith, A. (2001). Pathways to language: from fetus to adolescent. Cambridge, MA: Harvard University Press.

11- Hanoura, M., Hamid, A. (2002). Stanford Binet Intelligence test: Arabic Version. Cairo: Anglo Press.

12- Kotby, M.N., Khairy, A., Barakah, M., Rifaie, N. and El-Shobary, A. (1995). Language testing of Arabic speaking children. Proceeding of the XVIII World Congress of the International Association of Logopedics and Phoniatrics, (WCIALP'95), Cairo, Egypt, pp: 263-266.

13- Jersild, A.T. (1968). Child psychology. (6th ed.) Englewood Cliffs, N.J: Prentice-Hall.

14- Vygotsky, L. (1986). 'Thought and Language.' Cambridge, MA: MIT Press.

15- Gathercole, S.E., Hitch, G.J., Service, E. \& Martin, A.J. (1997). Short-term memory and long-term learning in children. Developmental Psychology, 33, 966-979.

16- Bowey, J.A. (2001). Non-word repetition and young children's receptive vocabulary: A longitudinal 
study. Applied Psycholinguistics, 22, 441-469.

17- Gathercole, S.E., Willis, C.S., Emslie, H. \&Baddeley, A.D. (1992). Phonological memory and vocabulary development during the early school years: A longitudinal study. Developmental Psychology, 28, 887-898. doi: 10.1037/00121649.28.5.887

18- Melby-Lervag, M., Lervag, A., Lyster, S.A., Klem, M., Hagtvet, B. \&Hulme, C. (2012). Nonwordrepetition ability does not appear to be a causal influence on children's vocabulary development. Psychological Science, 23, 1092$1098 . \quad$ doi:

10.1177/0956797612443833

19- Alloway, T.P., Rajendran, G., Archibald, L.M.D. (2009). Working Memory in Children with Developmental Disorders. Journal of Learning Disabilities, 42 (4): 372-282.

20- Rescorla, L. \& Roberts, J. (1997). Late talkers at 2: Outcome at age 3. Journal of Speech, Language \& Hearing Research, 40, 556-566.

21- Rice, M.L., Taylor, C. \&Zubrick, S. (2008). Language outcomes of seven-year-old children with or without a history of late language emergence at months. Journal of Speech, Language \& Hearing Research, 51, 394-407.

22-Weismer, S., Murray-Branch, J. \& Miller, J.F. (1994). A prospective longitudinal study of language development in late talkers. Journal of Speech and Hearing Research, 37, 852-867.

23- Price, T.S., Eley, T.C., Dale P.S., Stevenson, J., Saudino, K., \&Plomin R. (2000). Genetic and environmental co variation between verbal and nonverbal cognitive development in infancy. Child Development, 71, 948-959. 